\title{
A panel of new thermostable CYP116B self-sufficient cytochrome P450 monooxygenases catalysing C-H activation with diverse substrate scope
} DOI:

10.1002/cctc. 201701510

\section{Document Version}

Accepted author manuscript

Link to publication record in Manchester Research Explorer

Citation for published version (APA):

Tavanti, M., Porter, J., Sabatini, S., Turner, N., \& Flitsch, S. (2017). A panel of new thermostable CYP116B selfsufficient cytochrome P450 monooxygenases catalysing C-H activation with diverse substrate scope.

ChemCatChem. https://doi.org/10.1002/cctc.201701510

\section{Published in:}

ChemCatChem

\section{Citing this paper}

Please note that where the full-text provided on Manchester Research Explorer is the Author Accepted Manuscript or Proof version this may differ from the final Published version. If citing, it is advised that you check and use the publisher's definitive version.

\section{General rights}

Copyright and moral rights for the publications made accessible in the Research Explorer are retained by the authors and/or other copyright owners and it is a condition of accessing publications that users recognise and abide by the legal requirements associated with these rights.

\section{Takedown policy}

If you believe that this document breaches copyright please refer to the University of Manchester's Takedown Procedures [http://man.ac.uk/04Y6Bo] or contact uml.scholarlycommunications@manchester.ac.uk providing relevant details, so we can investigate your claim.

\section{OPEN ACCESS}




\title{
A panel of new thermostable CYP116B self-sufficient cytochrome P450 monooxygenases catalysing $\mathrm{C}-\mathrm{H}$ activation with diverse substrate scope
}

\author{
Michele Tavanti, Joanne L. Porter, Selina Sabatini, Nicholas J. Turner* and Sabine L. Flitsch*
}

School of Chemistry, Manchester Institute of Biotechnology, University of Manchester, 131 Princess

Street, Manchester M1 7DN, UK

E-mail: Nicholas.turner@manchester.ac.uk and sabine.flitsch@manchester.ac.uk

\begin{abstract}
The ability of cytochrome $\mathrm{P} 450$ monooxygenases to catalyse a wide variety of synthetically challenging $\mathrm{C}-\mathrm{H}$ activation reactions makes them highly desirable biocatalysts both for the synthesis of chiral intermediates and for late stage functionalisations. However, P450s are plagued by issues associated with poor expression, solubility and stability. Catalytically self-sufficient P450s, in which the haem and reductase domains are fused in a single protein, obviate the need for additional redox partners and are attractive as biocatalysts. Here we present a panel of natural self-sufficient P450s from thermophilic organisms (CYP116B65 from A. thermoflava, CYP116B64 from A. xiamenense, CYP116B63 from J. thermophila, CYP116B29 from T. bispora and CYP116B46 from T. thermophilus). These P450s display enhanced expression and stability over their mesophilic homologues. Activity profiling of these enzymes revealed that each P450 displayed a different fingerprint in terms of substrate range and reactivity covering reactions as diverse as hydroxylation, demethylation, epoxidation and sulphoxidation. The productivity of the biotransformation of diclofenac to produce the 5-hydroxy metabolite rose by 42 -fold using the thermostable P450-AX (> $0.5 \mathrm{~g} \mathrm{~L}^{-1} \mathrm{~h}^{-1}$ ) compared to the previously reported P450-RhF system. In conclusion, we have generated a toolkit of thermostable self-sufficient $\mathrm{P} 450$ biocatalysts, with broad substrate range and reactivity.
\end{abstract}

\section{Introduction}

Cytochromes P450 (P450s) are a superfamily of haem-thiolate enzymes that are ubiquitous in Nature and play a primary role in drug metabolism and the biosynthesis of physiologically important compounds including steroids and vitamins. ${ }^{[1]}$ $\mathrm{P} 450$ s have the ability to catalyse a wide range of synthetically challenging $\mathrm{C}-\mathrm{H}$ activation reactions with high levels of regio- and stereoselectivity. ${ }^{[2]}$ The most common $\mathrm{P} 450$ catalysed reactions are monooygenation reactions (e.g. hydroxylations, heteroatom oxidations or epoxidations) using a single oxygen atom from molecular oxygen, with the other oxygen atom reduced to water (Figure $1 A$ ). Two electrons supplied by $N A D(P) H$ are shuttled following productive interaction with redox partners to enable molecular oxygen activation. ${ }^{[3]}$ Less common $\mathrm{P} 450$ reactions also include $\mathrm{N}$ - and O- dealkylations, desaturations, ring formations and expansions, oxidative ester cleavage and isomerisation. ${ }^{[4]}$ As such, P450s have immense potential as biocatalysts due to the challenging nature and wide range of chemistry they can facilitate and present a green alternative or partner to chemocatalysis. ${ }^{[5]}$ However despite these attractive features, the number of P450s in use industrially are limited. ${ }^{[6]}$ The key factors limiting their widespread application include low levels of expression, poor solubility and/or stability particularly in recombinant systems, narrow substrate scope and production cost of the biocatalyst. ${ }^{[6-7]}$ 

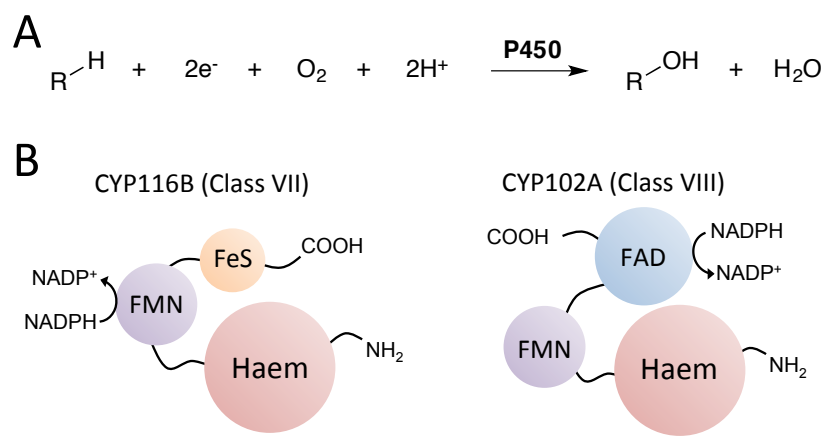

Figure 1. (A) P450-catalysed oxidations, including C-H activation and (B) structural organisation of CYP116B and CYP102A self-sufficient P450s.

Previous studies have looked at the genomes of thermophilic organisms in order to identify more suitable biocatalysts. Nevertheless the number of P450s from thermophilic microorganisms that have been studied so far is few, including CYP119A1 from S. solfataricus, ${ }^{[12]}$ CYP119A2 (P450st) from S. tokodaii, ${ }^{[13]}$ CYP154H1 from T. fusca ${ }^{[14]}$ and CYP175A1 from $T$. thermophilus, ${ }^{[15]}$ Given that required redox partners are also proteins, applications require not only thermostable haem proteins, but also the co-expression or addition of independent thermostable redox partners. In some cases the corresponding native thermophilic electron transport system has been identified, however their discovery is no simple task. $^{[12 c, 16]}$ More conveniently, mesophilic reductase domains have been employed but limit the overall stability and coupling efficiency of the system to the stability of the most labile protein component. ${ }^{[12 a, 14]}$

The self-sufficient nature of class VII (e.g. CYP116B2, P450-RhF) and class VIII (e.g. CYP102A1, P450-BM3) P450s containing the haem and reductase domains on a single polypeptide strand makes them desirable biocatalysts, as the need for identification and separate expression of redox partners is negated (Figure 1B). Isolated from the mesophilic bacterium Bacillus megaterium, P450 BM3 fatty acid hydroxylase is the best studied self-sufficient P450. ${ }^{[17]}$ The subsequently discovered class VII self-sufficient enzymes include the mesophilic P450-RhF from Rhodococcus sp. NCIMB 9784, ${ }^{[18]}$ which displays a varied range of activities, ${ }^{[19]}$ including hydroxylation of the widely used anti-inflammatory drug diclofenac. ${ }^{[20]} \mathrm{P} 450-\mathrm{RhF}$ has a unique FMN and $2 \mathrm{Fe}-2 \mathrm{~S}$ ferredoxin containing phthalate dioxygenase-type reductase domain fused to the C-terminus of the P450 to create a monomeric $85-k D a$ self-sufficient enzyme. ${ }^{[18 a, 21]}$ The reductase domain has been exploited to create artificial fusion proteins with various independent haem domains. These chimeric constructs have been used for benzylic oxidation reactions and the production of drugs and drug metabolites. ${ }^{[22]}$ For example, the RhF reductase domain was fused to the engineered P450 Prava and utilised in the single step fermentative production of the cholesterol lowering drug pravastatin. ${ }^{[23]}$ However the stability of both the native and artificial constructs is poor, with previous results showing that upon purification the native enzyme is largely inactive due to instability of the FMN-FeS reductase domain. ${ }^{[20]}$

The idea of combining thermostability and catalytic self-sufficiency to create a robust biocatalyst is very attractive. Recently a fungal BM3 homologue from M. thermophilia has been isolated and characterised. However CO-binding studies monitoring conversion from P450 to the inactive P420 form with increasing temperature gave a $T_{50}$ value of only $43{ }^{\circ} \mathrm{C},{ }^{[24]}$ which is comparable to the mesophilic BM3. ${ }^{[25]}$ Alternatively, engineering studies have been directed towards creating thermostable self-sufficient enzymes. For example, thermostable P450 chimeras have been generated by exchange of the BM3 reductase domain with the more stable one from the homologue CYP102A3 or through structureguided SCHEMA recombination of the haem domains of CYP102A homologues. ${ }^{[26]}$ In another study the haem domain of CYP175A1 was linked to its native redox partners to give an artificial fusion protein displaying $50 \%$ residual activity after incubation at $80^{\circ} \mathrm{C}$ for 10 minutes. ${ }^{[27]}$

Here, our aim was to identify natural P450s from thermophilic origins that could outperform their mesophilic counterparts in terms of expression, solubility and stability in recombinant systems. In particular, we sought self-sufficient P450s to avoid the search for redox partners with matching thermostability and to simplify protein production. Thus, the thermal stability and catalytic properties of five class VII P450s have been investigated and compared to that of P450-RhF. Given that these multi-domain catalysts have evolved each in thermostable organisms, it was also interesting to ask if the 
observed thermostability would be the same for all subdomains, or if one of the domains consistently displayed higher stability in these five systems.

\section{Results and Discussion}

\section{Identification of RhF homologues from thermophiles}

Initially BLAST searches of nucleotide and protein databases were carried out using P450-BM3 or P450-RhF as the query sequence to identify homologues from thermophilic bacteria. Several BM3 homologues were identified from thermophilic organisms, however most were fungal (Table S1). Due to the interesting range of activity displayed by P450-RhF, as outlined above, we selected five RhF homologues from thermophilic bacteria for characterisation: CYP116B65 (P450-AT) from Amycolatopsis thermoflava, CYP116B64 (P450-AX) from Albidovulum xiamenense, CYP116B63 (P450-JT) from Jhaorihella thermophila, CYP116B29 (P450-TB) from Thermobispora bispora and CYP116B46 (P450-TT) from Tepidiphilus thermophilus (Table 1). The amino acid sequences were aligned and the amino acid compositions were assessed (Figure S1, S2 and Table S2, Supporting Information). It has been commonly observed that thermophilic enzymes have an increased number of hydrophobic and aromatic interactions as well as more $\mathrm{H}$-bonding and ionic interactions. ${ }^{[28]}$ As such the amino acid composition of thermophiles can show trends towards larger non-polar, aromatic and charged amino acids at the expense of small non-polar and polar uncharged residues. ${ }^{[10 c, 29]}$ Here general trends could be observed with fewer Ala and an increase in lle, Phe and Arg residues with increasing thermal stability, though it is difficult to rationalise without structural context.

Table 1. Sequence information for P450-RhF and the identified homologues AT, AX, JT, TB and TT

\begin{tabular}{|c|c|c|c|c|c|}
\hline P450 & MW (kDa) & CYP number & Organism & $\begin{array}{l}\text { Cultivation } \\
\text { temperature }^{[\mathrm{a}]}\end{array}$ & Source \\
\hline $\mathrm{RhF}$ & 85.3 & CYP116B2 & Rhodococcus sp. NCIMB strain 9784 & $25^{\circ} \mathrm{C}$ & Soil \\
\hline AT & 84.9 & CYP116B65 & Amycolatopsis thermoflava DSM strain 44574 & $45^{\circ} \mathrm{C}$ & Soil, China \\
\hline$A X$ & 86.0 & CYP116B64 & Albidovulum xiamenense DSM strain 24422 & $55^{\circ} \mathrm{C}$ & $\begin{array}{l}\text { Terrestrial hot spring, } \\
\text { China }\end{array}$ \\
\hline JT & 86.5 & CYP116B63 & Jhaorihella thermophila DSM strain 23413 & $28^{\circ} \mathrm{C}$ & $\begin{array}{l}\text { Coastal hot spring, } \\
\text { Taiwan }\end{array}$ \\
\hline TB & 87.2 & CYP116B29 & Thermobispora bispora DSM strain 43833 & $45^{\circ} \mathrm{C}$ & Decaying manure \\
\hline TT & 89.4 & CYP116B46 & Tepidiphilus thermophilus DSM strain 27220 & $50^{\circ} \mathrm{C}$ & $\begin{array}{l}\text { Terrestrial hot spring, } \\
\text { India }\end{array}$ \\
\hline
\end{tabular}

${ }^{\text {a] }}$ Cultivation conditions for microorganisms were obtained from the NCIMB or DSMZ catalogues. 


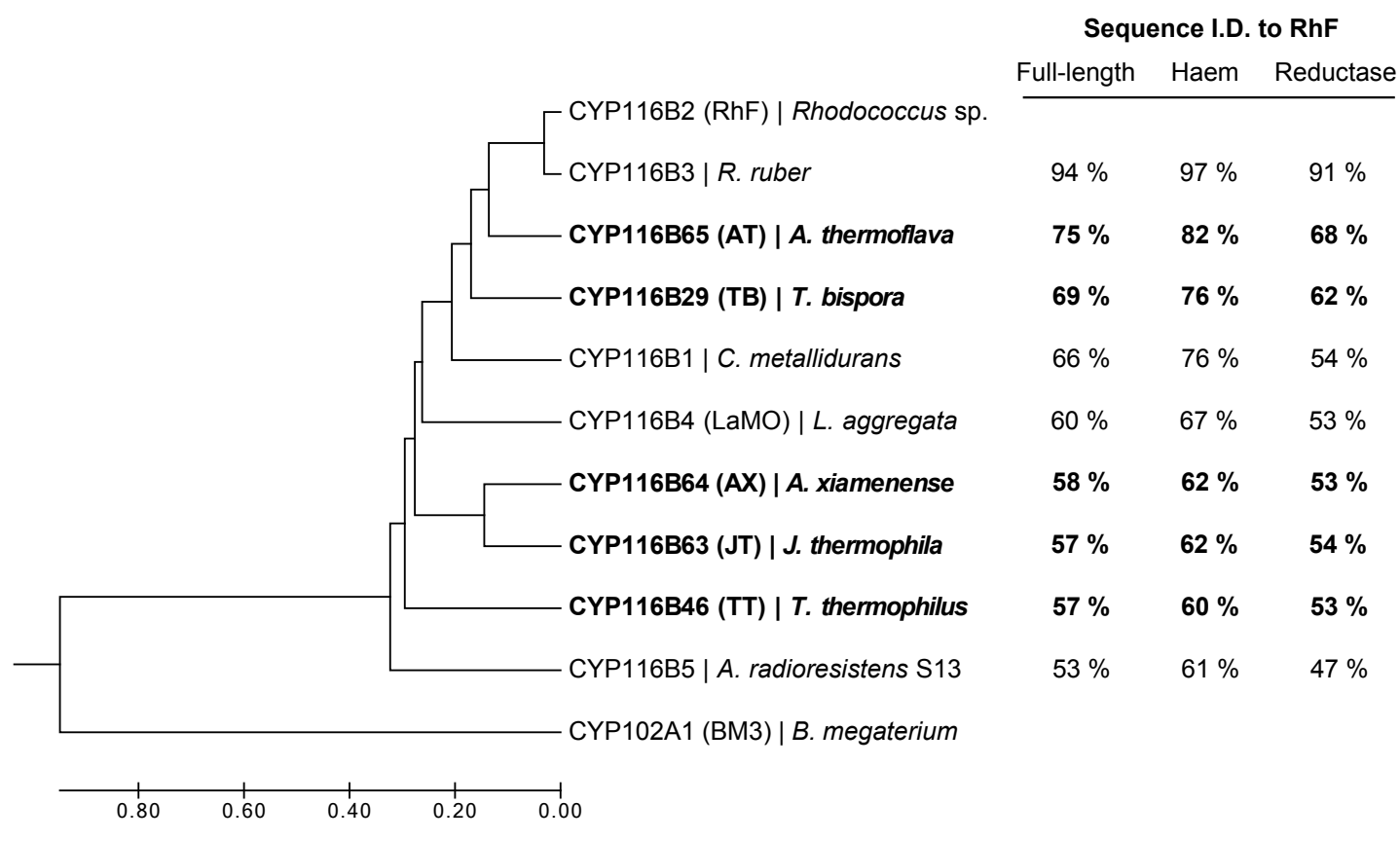

Figure 2. Phylogenetic tree with new and previously reported Class VII P450s as well as the Class VIII BM3. The evolutionary analyses were conducted in MEGA7 with sequences aligned using ClustalW and evolutionary history inferred using the UPGMA method. The evolutionary distances were calculated using the Poisson correction method and are in the units of number of amino acids substitutions per site.

A phylogenetic tree was constructed with the five new sequences and the five previously characterised class VII CYP116B enzymes (Figure 2). Preliminary data exists for several proposed class VII enzymes, ${ }^{[30]}$ however the number of fully characterised class VII enzymes is very limited with only five previously published (CYP116B1 from C. metallidurans, CYP116B3 from $R$. ruber, CYP116B4 from L. aggregata, CYP116B5 from A. radioresistens and the previously mentioned CYP116B2 RhF). ${ }^{[18 b, 31]}$ Unsurprisingly due to the small number of thoroughly characterised sequences, there is less sequence identity than would otherwise be expected from more populated classes such as the class VIII CYP102A enzymes (Figure 2 and Figure S3, Supporting Information). The most closely related to RhF is P450-AT with $75 \%$ sequence identity, followed by TB with $69 \%$ identity. In all cases there is closer homology between the haem domains than the reductase domains.

\section{Expression, purification and UV-visible absorption properties of thermophilic class VII P450s}

The genes encoding P450 AT, AX, JT, TB and TT were cloned from genomic DNA into pET28a and expressed in Escherichia coli BL21(DE3) with cleavable polyhistidine tags. SDS-PAGE analysis showed overexpression of the correct size constructs $(\mathrm{AT}=87.0, \mathrm{AX}=88.2, \mathrm{JT}=88.7, \mathrm{~TB}=90.8$ and $\mathrm{TT}=93.0 \mathrm{kDa}$ ) with good levels of soluble protein (Figure S4, Supporting Information). The P450 concentration was measured in the corresponding cell lysates with the new panel of P450s showing up to 5.6-fold better expression and stability during the lysis process compared to RhF (TT $=315.5$ and $\mathrm{RhF}=56.1 \mathrm{nmol}_{\mathrm{P} 450} \mathrm{~g}_{\mathrm{cdw}}{ }^{-1}$ ) (Table S4, Supporting Information). The new panel of enzymes were purified by IMAC following sonication of whole cells expressing the respective P450. The purified samples were subsequently analysed by SDS- PAGE and showed purification of the full-length enzymes (Figure S5, Supporting Information).

The UV-visible absorption features of the newly expressed and IMAC purified P450s were characteristic of typical P450 haemoproteins (Figure S6, Supporting Information). The oxidised form of the purified proteins gave spectra with the absorption maximum of the main Soret band at $419 \mathrm{~nm}$ and the $\alpha$ and $\beta$ bands located at 567 and $533 \mathrm{~nm}$ respectively for AT. Similarly the main Soret band and the $\alpha$ and $\beta$ bands were located at 422,567 and $536 \mathrm{~nm}$ for AX, 420, 568 and 530 $\mathrm{nm}$ for JT, 420, 570 and $532 \mathrm{~nm}$ for TB and 420, 568 and $537 \mathrm{~nm}$ for TT. Reduction with sodium dithionite causes a slight shift in the main Soret band $(<420 \mathrm{~nm})$ and for it to diminish in intensity. The addition of $\mathrm{CO}$ to the dithionite-reduced 
samples causes the expected shift in absorption to 449-451 nm (449, 451, 450, 449 and $449 \mathrm{~nm}$ for AT, AX, JT, TB and TT respectively) upon formation of an Fe(II)-CO complex, which is where the P450 name derives.

\section{Substrate scope and nucleotide cofactor preference}

Prior to investigation of the substrate scope the cofactor preference of the class VII P450s AT, AX, JT, TB and TT was determined monitoring the reduction of cytochrome $c$ as the electron acceptor in steady-state reactions. Both NADH and NADPH were tested as electron donors but there was a strong preference observed for NADPH over NADH in all cases (Table S6, Supporting Information). This is consistent with the previously characterised Class VII enzymes CYP116B1, B2, B3 and B4 all of which also showed preference toward NADPH. ${ }^{[18 a, 31 a, 31 c, 31 d]}$ The observed $k_{\text {cat }}$ value of $5.6 \pm 0.7,8.3$ \pm 0.7 and $40.5 \pm 0.8 \mathrm{~s}^{-1}$ for $\mathrm{NADPH}$ as electron donor by TB, AX and TT is in the same range as those previously determined for CYP116B1-3 $\left(k_{\text {cat }}=2.5-39 \mathrm{~s}^{-1}\right)$, however AT and JT exhibit higher rates with $k_{\text {cat }}$ values of $69 \pm 2$ and 70 $\pm 2 \mathrm{~s}^{-1}$ respectively.

P450-RhF displays a notable degree of substrate promiscuity, being able to catalyse not only hydroxylation reactions but also the O-dealkylation, sulfoxidation and epoxidation of a diverse range of compounds. ${ }^{[19]}$ We assembled twelve such compounds creating a test set with which to explore the substrate scope of P450-AT, AX, JT, TB and TT. Reactions were run using soluble cell lysates (the equivalent of $200 \mathrm{mg} \mathrm{mL}^{-1}$ wet cell weight) (P450 concentrations determined by CO binding are shown in Table S8, Supporting Information) for $20 \mathrm{~h}$ with NADP ${ }^{+}$and a cofactor recycling system consisting of glucose and glucose dehydrogenase $(\mathrm{GDH})$ to facilitate production of the more expensive NADPH (Table 2).

Table 2 shows the total substrate conversions catalysed by each enzyme including RhF. In most cases the major product could be identified by comparison with an authentic standard. The number and approximate distribution of unidentified products have also been indicated in order to provide a general fingerprint ${ }^{[32]}$ of the respective enzyme activities (Table 2). A range of activity was observed including demethylation, epoxidation, hydroxylation, and sulphoxidation. Previously P450-RhF has been shown to possess good activity towards diclofenac (1) and produce the human metabolite 5-hydroxydiclofenac (2) ${ }^{[20]}$ In this study P450-AT, AX, JT and TT all displayed better conversions (> 85 $\%)$ to the hydroxylated product than $\mathrm{RhF}(63 \%)$ under the screening conditions. Furthermore in terms of total substrate conversion, RhF was outperformed in all cases by two or more of the new class VII P450s from this study, with the exception of just $\alpha$-isophorone (17) and tetradecane (22) where no activity was observed with any P450. Demethylation was observed for P450 biotransformations with 4-methyoxyacetophenone (3), 2-hydroxy-4-methoxyacetophenone (5), 4methoxybenzophenone (7), 4-methoxybenzonitrile (9) and 7-methoxycoumarin (11) and the demethylated compound was the major product in most cases.

Hydroxylation was observed with fluorene (13) to give 9-fluorenol (14) as the major product. In addition, benzylic C-H activation of ethylbenzene (15) resulted in $35 \%$ conversion by AT, $8 \%$ by JT and $13 \%$ by TB, to produce (S)-1phenylethanol (16) (90 $\pm 10 \%$ ee) (Table S10, Supporting Information). Furthermore the sulphoxidation capability of AT, AX, JT, TB and TT was demonstrated with methyl phenyl sulphide (18) to give conversions of $59,34,58,58$ and $21 \%$ respectively to the corresponding sulfoxide 19 (predominantly $(S)$-methyl phenyl sulfoxide). Epoxidation activity was also demonstrated using styrene $(20)$ as substrate with conversions of $10-20 \%$ to give the epoxide 21 as a racemate catalysed by AT, JT and TB. 


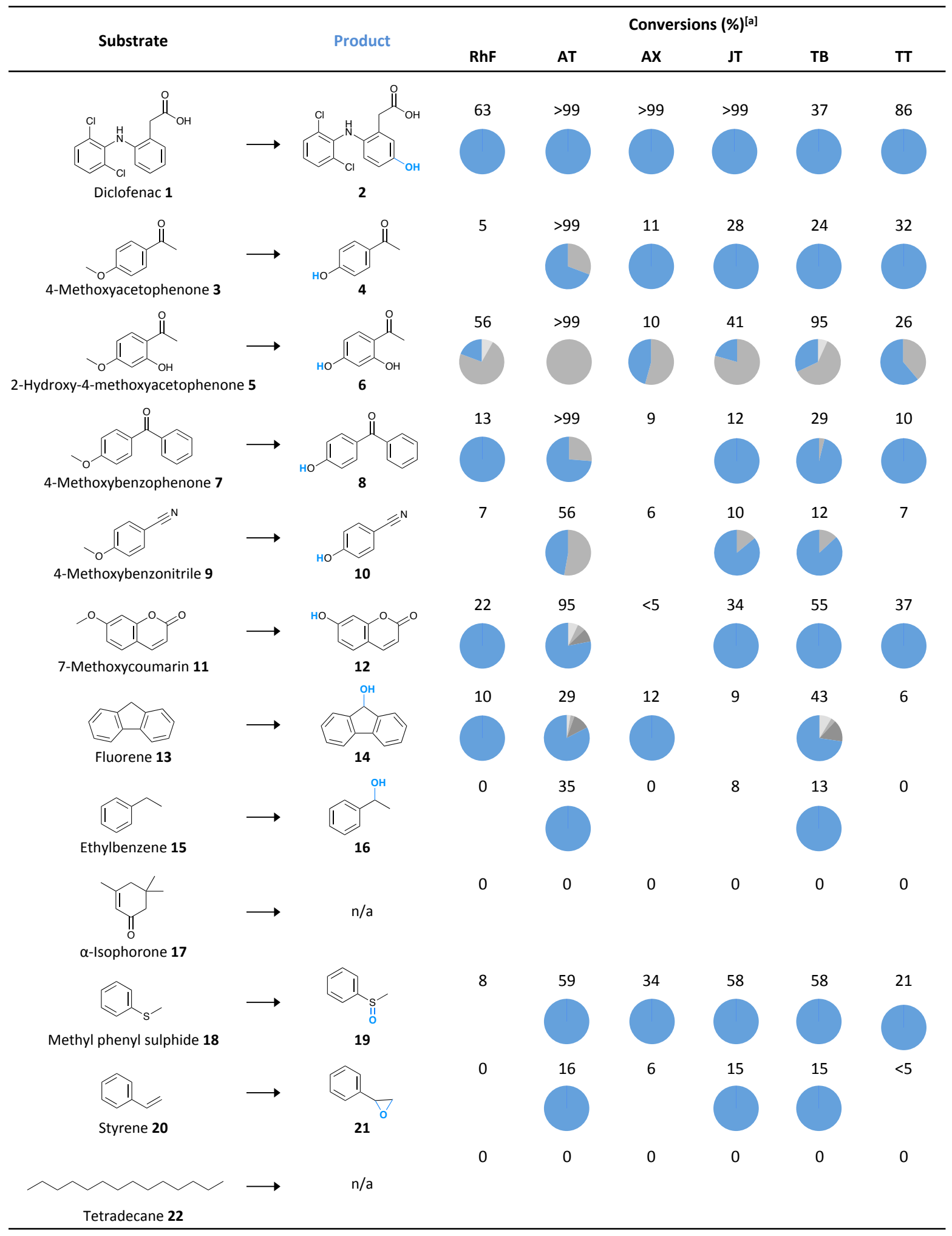

${ }^{\text {[a] }}$ Reactions were carried out using soluble cell lysates. Product fingerprints are indicated in the charts under the respective conversion value with blue indicating a product identified through comparison with an authentic standard and grey indicating unidentified product(s) (fingerprints are not given where substrate conversion is less than $10 \%)$.

\section{Thermal stability of the P450 panel}

Previous literature on thermostable P450s placed the major focus on the stability of the haem domain at high temperatures. However, P450 chemistry depends also on the effective supply of reducing equivalents from redox 
partners, the stability of which needs to match the haem domain. As we were interested in the overall construct stability, the thermal stability of the P450s was measured in two ways, (i) determining the residual $\mathrm{CO}$ binding by formation of the $\mathrm{Fe}$ (II)-CO complex at $450 \mathrm{~nm}$ and (ii) by monitoring the residual activity toward 7-methoxycoumarin (11). The plots showing P450 concentration determined by $\mathrm{CO}$ binding were obtained using cell-free lysates and include P450-RhF for comparison (Figure $3 \mathrm{~A}$ ). Each of the P450s from this study displayed greater thermal stability than RhF, which was encouraging given the previous issues with stability of P450-RhF. ${ }^{[20]}$ P450 AT and JT showed modest improvements from RhF, while AX, TB and TT showed significant improvements with increases in $T_{50}$ of greater than $15{ }^{\circ} \mathrm{C}$. The residual activity experiments shown in Figure 3B were conducted using purified protein and demonstrate not only thermal stability but also confirm the self-sufficient nature of these P450s. RhF is not stable during routine purification and is therefore not included for comparison. ${ }^{[20]}$ Similarly to the data shown in Figure $3 \mathrm{~A}$, the P450s exhibiting the greatest stability determined by residual activity were TB, AX and TT. These operating temperatures are largely consistent with the growth temperatures of their native hosts $(\mathrm{JT}<\mathrm{AT}=\mathrm{TB}<\mathrm{TT}<\mathrm{AX})($ Table 1$)$.
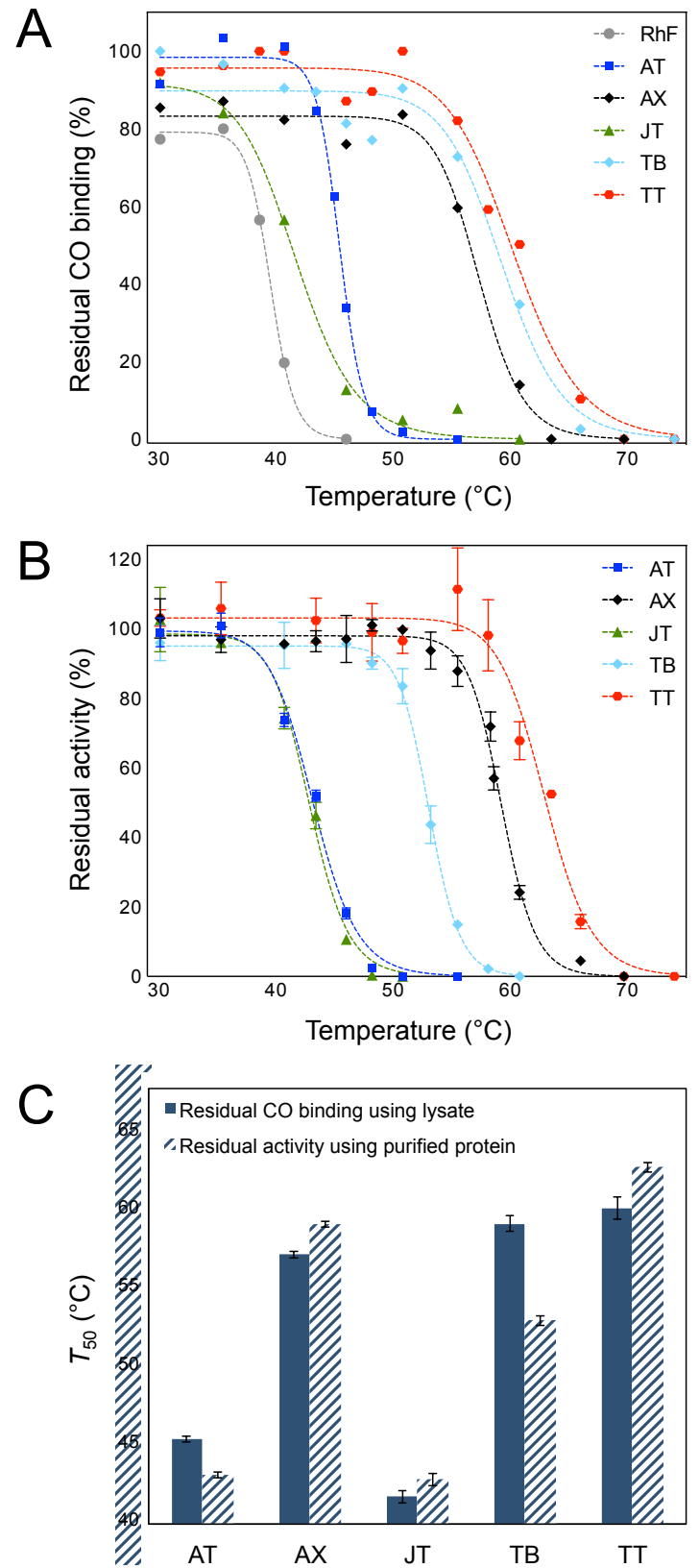

Figure 3. Thermal stability of $\mathrm{P} 450$ s assessed by $(\mathrm{A})$ the residual $\mathrm{CO}$ binding following incubation of soluble cell lysates at elevated temperature for $15 \mathrm{~min}$ and $(\mathrm{B})$ the residual activity toward 7-methoxycoumarin following incubation at elevated temperature 15 min with (C) the corresponding $T_{50}$ values determined from either method. 
Values for $T_{50}$ were extracted by fitting the data to a Hill type equation (Page S14, Supporting Information) and are compared in Figure 3C. In most cases there are small discrepancies between the observed $T_{50}$ values for the residual CO binding and the residual activity, but for AT, AX, JT and TT these differences are less than $3{ }^{\circ} \mathrm{C}$. Differences are expected due to the different experimental setup and the use of lysate for the $\mathrm{CO}$ binding compared to the use of purified protein with a defined buffer composition used for the residual activity. However, in the case of P450-TB (and AT to a lesser extent) the $T_{50}$ values determined by each method differ significantly. The $T_{50}$ determined by CO binding (TB: $T_{50}=59.3 \pm$ $0.7^{\circ} \mathrm{C}$ ) is greater than the $T_{50}$ determined by residual activity (TB: $T_{50}=53.1 \pm 0.3^{\circ} \mathrm{C}$ ) by $6.2 \pm 1{ }^{\circ} \mathrm{C}$. The source of difference can likely be attributed to a less stable reductase domain for TB since the CO binding is concerned purely with the integrity of the haem domain, while the residual activity requires function of the entire construct from electron transport through the FMN-FeS domain to substrate turnover in the haem domain.

To ascertain the relative stability of the P450 reductase domains compared to their partner haem domains, residual electron transfer was measured using cytochrome $c$ as electron acceptor following incubation at the individual $T_{50}$ determined by $\mathrm{CO}$ binding (where residual activity $>50 \%$ would suggest a more stable reductase domain compared to the corresponding haem domain and residual activity < $50 \%$ would suggest a less stable reductase domain) (Figure 4). The residual electron transfer values were in accordance with the residual activities observed for 7-methoxycoumarin (11). Under these experimental conditions the AX, JT, and TT reductase domains showed equal or greater stability than their fused haem domains (similarly to the results in Figure $3 \mathrm{C}$ ), while as expected the TB and AT reductase domains were mostly inactive following incubation. This indicates a comparatively less stable reductase than haem domain and suggests that electron transport is indeed the limiting factor influencing substrate turnover at higher temperatures. This agrees with previous reports that the reductase domain of these self-sufficient enzymes may be responsible for reduced stability of the whole construct. $^{[20,26 a]}$

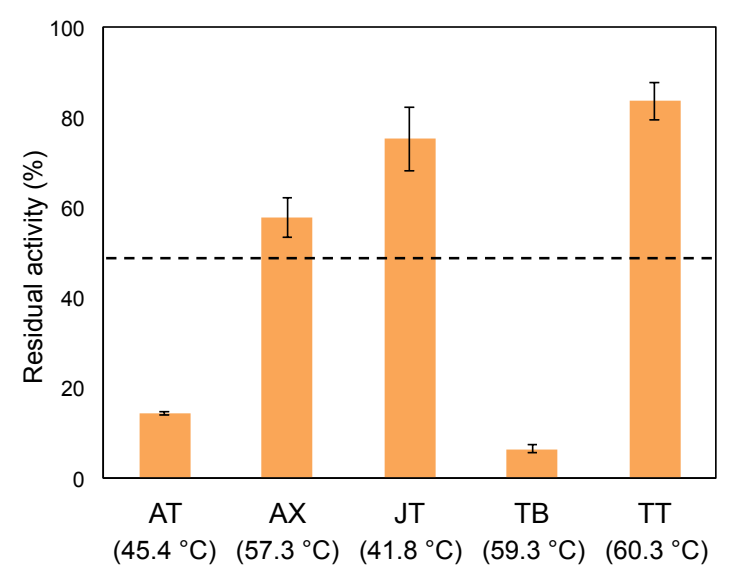

Figure 4. Residual electron transfer monitored by cytochrome $c$ reduction following heat treatment at the $T_{50}$ calculated by $\mathrm{CO}$ binding, where (---) shows the $50 \%$ residual $\mathrm{CO}$ binding at the indicated temperature.

The P450 displaying the highest stability through either experimental method was TT. To assess not only maximum temperature stability but also the stability at moderate temperatures over longer periods, half-life assays were conducted at 50 and $58{ }^{\circ} \mathrm{C}$ (Figure S8, Supporting Information). TT displayed a half-life of approximately $9.5 \mathrm{~h}$ with incubation at $50{ }^{\circ} \mathrm{C}$, while the half-life was reduced to approximately $2 \mathrm{~h}$ at $58{ }^{\circ} \mathrm{C}$. In addition, further studies were conducted investigating the kinetic parameters of P450-TT. Having already established the preference for NADPH and determined the kinetic properties at $25^{\circ} \mathrm{C}$ (Table S6, Supporting Information), we wanted to see if conducting the reaction at higher temperature yielded an increase in electron transfer rate (Table S7, Supporting Information). At $50{ }^{\circ} \mathrm{C}$ using NADPH as substrate with cytochrome $c$ as electron acceptor the $k_{\text {cat }}$ value was $80 \pm 2 \mathrm{~s}^{-1}$ which is approximately double the rate when the reaction was performed at the lower temperature of $25^{\circ} \mathrm{C}\left(k_{\mathrm{cat}}=40.4 \pm 0.8 \mathrm{~s}^{-1}\right)$. 


\section{Whole cell biotransformations of diclofenac}

Diclofenac (1) is a widely used non-steroidal anti-inflammatory drug that along with its 4'-hydroxy and 5-hydroxy 2 metabolites is persistent in the environment due to low biodegradability. The P450-RhF catalysed hydroxylation of diclofenac (1) in an E. coli whole cell system has been previously reported for the regioselective production of 5hydroxydiclofenac (2). ${ }^{[20]}$ The production levels of $\mathrm{P} 450-\mathrm{RhF}$ were comparable to those of P450-BM3 and good product yields $\left(0.29 \mathrm{~g} \mathrm{~L}^{-1}\right)$ were achieved using a substrate feeding strategy. However, when high concentrations ofsubstrate were added at the beginning of the reaction in a single batch, very low conversions were observed. Here our initial screening experiments (as discussed above) suggested that the present thermostable enzymes would be significantly better biocatalysts for this reaction (Table 2). To investigate the suitability of these P450s for the production of 5hydroxydiclofenac (2) whole cell biotransformations were conducted. Diclofenac $(1,2,10$ or $20 \mathrm{mM}$ final concentrations) was added in a single addition to start the reactions, which were carried out at both 20 and $40{ }^{\circ} \mathrm{C}$ (Figure 5).As a baseline for our investigations, we observed that P450-RhF catalysed the transformation of diclofenac (1) to produce 5hydroxydiclofenac $(2)(\sim 0.5 \mathrm{mM})$ with 1 and $2 \mathrm{mM}$ substrate loading at $20^{\circ} \mathrm{C}$ but not at higher substrate concentrations. Furthermore, for the whole cell biotransformations conducted at $40^{\circ} \mathrm{C}$ with P450-RhF (Figure $5 \mathrm{~B}$ ), there was no appreciable amount of product detected for any of the RhF catalysed reactions regardless of initial substrate concentration. When the temperature was raised to $40{ }^{\circ} \mathrm{C}$ and when using high substrate loading (10 and $\left.20 \mathrm{mM}\right), \mathrm{AX}, \mathrm{JT}$, TB and TT all outperform RhF in terms of final product titer. P450-AX also outperforms RhF under its optimum conditions of $20^{\circ} \mathrm{C}$ using 1 or $2 \mathrm{mM}$ diclofenac and in fact performed significantly better than not just RhF but also AT, JT, TB and TT under all of the tested conditions. It is interesting to note that increasing the temperature of the AX catalysed production of 5-hydroxydiclofenac (2) from 20 to $40{ }^{\circ} \mathrm{C}$ with a $10 \mathrm{mM}$ substrate loading led to a $100 \%$ increase in product formation.

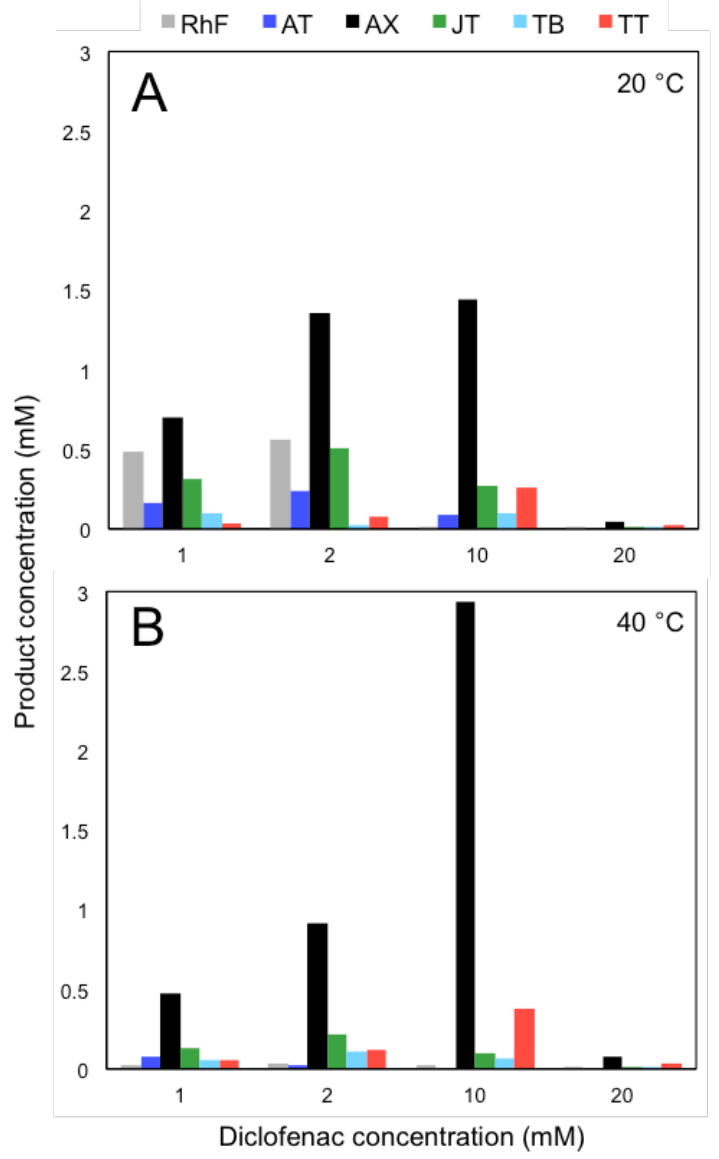

Figure 5. Whole cell biotransformations with 1, 2, 10 and $20 \mathrm{mM}$ diclofenac conducted at $(\mathbf{A}) 20^{\circ} \mathrm{C}$ and $($ B $) 40^{\circ} \mathrm{C}$ 
The scale-up of P450 based reactions at gram scale is still a challenge. ${ }^{[33]}$ The number of reported preparative and gram scale reactions is low, ${ }^{[34]}$ this is especially apparent in comparison to other enzyme systems. We aimed to assess scalability of the P450-AX whole cell biotransformation of diclofenac for comparison with the previous scale-up work with P450-RhF ${ }^{[20]}$ Accordingly, the reaction was scaled-up linearly from 0.5 to $100 \mathrm{~mL}$ with $10 \mathrm{mM}$ diclofenac and conducted at $40{ }^{\circ} \mathrm{C}$ as before. The reaction was monitored over time (Figure S9, Supporting information) and after 5-10 $\mathrm{h}$ a final product concentration of $5.0 \mathrm{mM}\left(1.6 \mathrm{~g} \mathrm{~L}^{-1}\right)$ was obtained, corresponding to a conversion of $50 \%$, with some substrate and/or product loss to the biomass. Production of the 5-hydroxydiclofenac metabolite (2) was confirmed by ${ }^{1} \mathrm{H}$ NMR spectroscopy (Page S16, Supporting information), which gave spectral data consistent with reported values. ${ }^{[20]}$ The whole cell system showed good scalability with a greater conversion in the scaled-up biotransformation than for the initial smallscale reactions $(2.9 \mathrm{mM})$.

Product formation plateaued after approximately $5 \mathrm{~h}$ (Figure S9, Supporting Information) at $50 \%$ conversion despite the use of a thermally stable P450 (AX: $T_{50}=59.3 \pm 0.2{ }^{\circ} \mathrm{C}$ ). This could be due to the use of whole cells rather than purified protein where mesophilic cellular enzymes are relied upon for cofactor recycling. Nevertheless, without any optimisation, the AX system showed more robustness with higher substrate loading and an impressive 42-fold improvement in productivity and a 150-fold improvement in maximum specific activity when compared to the previously reported metrics for the P450-RhF catalysed whole cell system (Table 3), ${ }^{[20]}$ making it a more suitable system for the production of 5-hydroxydiclofenac (2).

Uncoupling in P450 reactions is another important parameter to consider as it influences reaction rate and results in the formation of reactive oxygen species (ROS), which can effect the stability and performance of the whole system. ${ }^{\text {[3b] }}$ ROS are side products of P450 reactions occuring due to inefficient coupling of electrons from NADPH to formation of, in this case the hydroxylation product. The modified human P450 CYP2C9 catalyses the oxidation of diclofenac with a coupling efficiency of $\sim 30 \% .{ }^{[35]}$ Here the coupling efficiency of the AX catalysed hydroxylation of diclofenac is $51 \pm 3 \%$. In comparison with the self-sufficient BM3 with its native substrates where coupling is typically $>90 \%$, ${ }^{[36]}$ this value is slightly modest and could impact activity in whole cell reactions. ${ }^{[37]}$ However for other P450s and with non-physiological substrates, such high coupling efficiency is rare.

Table 3. Comparison of the RhF and AX catalysed production of 5-hydroxydiclofenac

\begin{tabular}{|c|c|c|}
\hline & P450-RhF ${ }^{[a]}$ & P450-AX \\
\hline \multirow{3}{*}{$\begin{array}{l}\text { Substrate loading } \\
\text { (delivery time) }\end{array}$} & $1 \mathrm{mM}(0 \mathrm{~h})$ & \\
\hline & $0.3 \mathrm{mM}(8 \mathrm{~h})$ & $10 \mathrm{mM}(0 \mathrm{~h})$ \\
\hline & $0.3 \mathrm{mM}(23 \mathrm{~h})$ & \\
\hline $\begin{array}{l}\text { Average productivity } \\
\left(\mathrm{g} \mathrm{L}^{-1} \mathrm{~h}^{-1}\right)\end{array}$ & 0.012 & 0.51 \\
\hline Product yield $\left(\mathrm{g} \mathrm{L}^{-1}\right)$ & 0.29 & 1.6 \\
\hline $\begin{array}{l}\text { Maximum specific activity } \\
\left(\mathrm{mg}_{\text {product }} \mathrm{h}^{-1} \mathrm{mg}_{\mathrm{P} 450^{-1}}\right)\end{array}$ & 0.07 & 11.8 \\
\hline
\end{tabular}

${ }^{[a]}$ Values determined from previously published results ${ }^{[20}$

\section{Conclusions}

Since our first discovery of P450-RhF, ${ }^{[18 b]}$ this class of self-sufficient P450 monooxygenases has found wide applications and a number of homologues have been identified. ${ }^{[31]}$ Here, we have presented a panel of five naturally self-sufficient P450s from thermophilic microorganisms. P450-AT (CYP116B65) from A.thermoflava, AX (CYP116B64) from A. xiamenense, JT (CYP116B63) from J. thermophila, TB (CYP116B29) from T. bispora and TT (CYP116B46) from $T$. thermophilus are novel catalytically self-sufficient class VII P450 monooxygenases. The need for identification and production of corresponding thermostable redox partners and the commonly encountered issues with stability of P450PFOR constructs, such as that of P450-RhF, have been successfully overcome by using these self-sufficient thermostable 
enzymes. AT, AX, JT, TB and TT can be expressed reliably in a recombinant $E$. coli system and have shown considerable thermal stability in comparison with P450-RhF. In particular P450-AX and TT showed high levels of soluble expression and excellent robustnesswith $T_{50}$ values for residual activity of $59.3 \pm 0.2$ and $62.9 \pm 0.3{ }^{\circ} \mathrm{C}$ respectively. TT maintained activity at $50{ }^{\circ} \mathrm{C}$ with a half-life of over $9 \mathrm{~h}$ and also displayed a significantly (100\%) enhanced electron transfer rate at higher temperatures. Furthermore assessment of thermal stability has highlighted that stability of the corresponding haem and reductase domains has not necessarily evolved equivalently. The reductase domains of P450-TB and AT may limit activity of the overall fusion enzyme at high temperatures, however JT, AX and TT show excellent stability over the entire multi-domain construct.

Activity profiling has shown these new class VII P450s to have different substrate fingerprints and to be capable of catalysing oxidation reactions, including aromatic hydroxylation, demethylation, epoxidation and sulphoxidation. In addition, whole cells expressing P450-AX have been used for the biotransformation of diclofenac to the human metabolite 5-hydroxydiclofenac at preparative scale. The stability, reproducibility and higher product yields compared to the previously reported RhF system make P450-AX an ideal candidate for the regioselective production of 5hydroxydiclofenac (2), which is required for toxicology studies and as a standard for environmental analysis and is difficult to access chemically. This panel of robust $\mathrm{P} 450$ s with differing substrate and reaction profiles is an important addition to the toolbox of biocatalysts available for biooxidations using molecular oxygen.

\section{Experimental Section}

For full experimental details please refer to the Supporting Information.

\section{P450 expression and purification}

The target genes were cloned from genomic DNA (DSMZ) into pET28a through In-Fusion cloning (Clonetech) and transformed into E. coli BL21(DE3). Transformed cells were inoculated, from a starter culture, into the M9 expression medium supplemented with $0.4 \%$ glucose, $0.05 \% \mathrm{FeCl}_{2}, 1 \mathrm{mM} \mathrm{MgSO}, 1 \mathrm{mM} \mathrm{CaCl}_{2}$ and kanamycin. Cultures were grown to OD600 0.8 then induced with IPTG $(0.4 \mathrm{mM})$ ans supplemented with 5-aminolevulinic acid. Expression was carried out at $20^{\circ} \mathrm{C}$ for $20 \mathrm{~h}$, cells were subsequently harvested by centrifugation. For purification, cells were resuspended and lysed by sonication then purified by immobilised metal ion affinity chromatography (IMAC). The target proteins were eluted with imidazole $(300 \mathrm{mM})$ and fractions were analysed for purity by SDS-PAGE. Determination of P450 concentration was performed on a Cary UV/Visible spectrophotometer (Agilent) following a previously described protocol. ${ }^{[38]}$

\section{Biotransformations}

Reactions were performed using clarified cell lysate at a final lysate concentration equivalent to $200 \mathrm{mg} \mathrm{mL}^{-1}$ wet cells. Reactions were carried out in $0.2 \mathrm{M} \mathrm{KPi} \mathrm{pH} 8$ with $1 \mathrm{mM}$ substrate, $2 \% \mathrm{DMSO}$ and $\mathrm{NADPH}^{+}$. A cofactor recycling system consisting of D-glucose and glucose dehydrogenase was added to facilitate production of the required NADPH.

\section{Assessment of thermal stability}

Thermal stability was assessed by either residual CO-binding or by residual activity following incubation at elevated temperature. For residual CO-binding, clarified cell lysates were heated to various temperatures $\left(30-80{ }^{\circ} \mathrm{C}\right)$ for $15 \mathrm{~min}$. Cellular debris was removed by centrifugation and the P450 concentration was measured by CO-binding as described previously. ${ }^{[38]}$ The residual P450 concentration was determined by comparison with protein aliquots not subjected to heat treatment. Data was obtained from single measurements due to the sample volume and time required for each measurement.

Residual activity was measured using the 7-methoxycoumarin (11) as substrate. Purified protein was incubated between $30-80^{\circ} \mathrm{C}$ for $15 \mathrm{~min}$, then the residual activity was monitored by formation of 7-hydroxycoumarin (12) on a plate reader (Tecan) with excitation at $397 \mathrm{~nm}$ and emission at $466 \mathrm{~nm}$. Data was obtained in triplicate and the error is the standard deviation. For either method, $T_{50}$ values were extracted by fitting a Hill type equation (Eq. 1, Supporting 
Information, Page S15), where $T_{50}$ is defined as the temperature at which $50 \%$ of the initial $450 \mathrm{~nm}$ band or activity toward 11 is retained.

\section{Acknowledgements}

The research leading to these results received funding from the European Union's Seventh Framework Programme for research, technological development and demonstration under grant agreement no. 613849 (BIOOX) and from the European Union's Horizon 2020 Programme for research and innovation actions H2020-LEIT BIO-2014-1 under grant agreement no. 635734 (ROBOX). Additionally we would like to thank Dr. Kirsty J. McLean for her valuable advice on the cytochrome $c$ assay.

Any statement made herein reflects only the views of the authors. The European Union is not liable for any use that may be made of the information contained herein.

Keywords: cytochrome P450 monooxygenase $\bullet$ biocatalysis $\cdot \mathrm{CYP} 116 \mathrm{~B} \cdot$ thermophilic enzymes $\bullet \mathrm{C}-\mathrm{H}$ activation

[1] (a) R. Bernhardt, J. Biotechnol. 2006, 124, 128-145; (b) D. R. Nelson, Human genomics 2009, 4, 59-65.

[2] (a) S. T. Jung, R. Lauchli, F. H. Arnold, Curr. Opin. Biotechnol. 2011, 22, 809-817; (b) R. Fasan, ACS Catalysis 2012, 2, $647-666$.

[3] F. Hannemann, A. Bichet, K. M. Ewen, R. Bernhardt, Biochim. Biophys. Acta, Gen. Subjects 2007, $1770,330-344$.

[4] (a) F. P. Guengerich, J. Biochem. Mol. Toxicol. 2007, 21, 163-168; (b) F. P. Guengerich, A. W. Munro, J. Biol. Chem. 2013, 288, 17065-17073; (c) E. M. Isin, F. P. Guengerich, Biochim. Biophys. Acta 2007, 1770, 314-329.

[5] (a) E. M. Carreira, N. J. Turner, M. Hönig, P. Sondermann, Angew. Chem. Int. Ed. 2017; (b) B. M. Nestl, S. C. Hammer, B. A. Nebel, B. Hauer, Angew. Chem. 2014, 53; (c) D. J. Pollard, J. M. Woodley, Trends Biotechnol. 2007, 25, 66--73; (d) J. L. Porter, R. A. Rusli, D. L. Ollis, ChemBioChem 2016, 17, 197--203; (e) N. J. Turner, E. O'Reilly, Nature Chemical Biology 2013, 9, 285-288.

[6] H. M. Girvan, A. W. Munro, Curr. Opin. Chem. Biol. 2016, 31, 136-145.

[7] (a) R. Bernhardt, V. B. Urlacher, Appl. Microbiol. Biotechnol. 2014, 98; (b) E. O'Reilly, V. Kohler, S. L. Flitsch, N. J. Turner, Chem. Commun. 2011, 47, 2490-2501.

[8] S. Goodwin, J. D. McPherson, W. R. McCombie, Nat. Rev. Genet. 2016, 17, 333-351.

[9] B. Van den Burg, Curr. Opin. Microbiol. 2003, 6, 213--218.

[10] (a) J. A. Littlechild, Frontiers in bioengineering and biotechnology 2015, 3, 161-161; (b) P. Turner, G. Mamo, E. N. Karlsson, Microb. Cell Fact. 2007, 6, 9-9; (c) C. Vieille, G. J. Zeikus, C. Vieille, Microbiol. Mol. Biol. Rev. 2001, 65, 1-43.

[11] (a) J. D. Bloom, S. T. Labthavikul, C. R. Otey, F. H. Arnold, PNAS 2006, 103, 5869-5874; (b) N. Tokuriki, D. S. Tawfik, Curr. Opin. Struct. Biol. 2009, 19, 596-604; cN. Tokuriki, D. S. Tawfil, Science 2009, 203-208.

[12] (a) L. S. Koo, R. A. Tschirret-Guth, W. E. Straub, P. Moënne-Loccoz, T. M. Loehr, P. R. Ortiz De Montellano, J. Biol. Chem. 2000, 275, 1411214123; (b) S.-Y. Park, K. Yamane, S.-i. Adachi, Y. Shiro, K. E. Weiss, S. a. Maves, S. G. Sligar, J. Inorg. Biochem. 2002, 91, 491-501; (c) A. V. Puchkaev, P. R. Ortiz De Montellano, Arch. Biochem. Biophys. 2005, 434, 169-177.

[13] (a) Y. Oku, A. Ohtaki, S. Kamitori, N. Nakamura, M. Yohda, H. Ohno, Y. Kawarabayasi, J. Inorg. Biochem. 2004, 98, 1194-1199; (b) A. V. Puchkaev, T. Wakagi, P. R. Ortiz de Montellano, JACS 2002, 124, 12682-12683.

[14] A. Schallmey, G. Den Besten, I. G. P. Teune, R. F. Kembaren, D. B. Janssen, Appl. Microbiol. Biotechnol. 2011, 89, $1475-1485$.

[15](a) R. K. Behera, S. Mazumdar, Int. J. Biol. Macromol. 2010, 46, 412-418; (b) J. K. Yano, F. Blasco, H. Li, R. D. Schmid, A. Henne, T. L. Poulos, J. Biol. Chem. 2003, 278, 608-616.

[16] T. Mandai, S. Fujiwara, S. Imaoka, FEBS J. 2009, 276, 2416-2429.

[17]A. W. Munro, D. G. Leys, K. J. McLean, K. R. Marshall, T. W. B. Ost, S. Daff, C. S. Miles, S. K. Chapman, D. A. Lysek, C. C. Moser, C. C. Page, P. L. Dutton, Trends Biochem. Sci 2002, 27, 250-257.

[18] (a) G. A. Roberts, A. Celik, D. J. B. Hunter, T. W. B. Ost, J. H. White, S. K. Chapman, N. J. Turner, S. L. Flitsch, J. Biol. Chem. 2003, 278, 48914-48920; (b) G. A. Roberts, G. Grogan, A. Greter, S. L. Flitsch, N. J. Turner, J. Bacteriol. 2002, 184, 3898--3908.

[19] (a) A. Celik, G. A. Roberts, J. H. White, S. K. Chapman, N. J. Turner, S. L. Flitsch, Chem. Commun. 2006, 4492-4494; (b) E. O'Reilly, M. Corbett, S. Hussain, P. P. Kelly, D. Richardson, S. L. Flitsch, N. J. Turner, Catal. Sci. Technol. 2013, 3, 1490-1492.

[20] J. M. Klenk, B. A. Nebel, J. L. Porter, J. K. Kulig, S. A. Hussain, S. M. Richter, M. Tavanti, N. J. Turner, M. A. Hayes, B. Hauer, S. L. Flitsch, Biotechnol. J. 2017, 12, 1600520.

[21] D. J. B. Hunter, G. A. Roberts, T. W. B. Ost, J. H. White, S. Mueller, N. J. Turner, S. L. Flitsch, S. K. Chapman, FEBS Lett. 2005, 579, 22152220 .

[22] (a) A. Eichler, Ł. Gricman, S. Herter, P. P. Kelly, N. J. Turner, J. Pleiss, S. L. Flitsch, ChemBioChem 2016, 17, 426-432; (b) P. P. Kelly, A Eichler, S. Herter, D. C. Kranz, N. J. Turner, S. L. Flitsch, Beilstein J. of Org. Chem. 2015, 11, 1713-1720; (c) J. K. Kulig, C. Spandolf, R. Hyde, A. C. Ruzzini, L. D. Eltis, G. Grönberg, M. A. Hayes, G. Grogan, Bioorg. Med. Chem. 2015, 23, 5603-5609. 
[23] K. J. McLean, M. Hans, B. Meijrink, W. B. van Scheppingen, A. Vollebregt, K. L. Tee, J.-M. van der Laan, D. Leys, A. W. Munro, M. A. van den Berg, PNAS 2015, 112, 2847-2852.

[24] G. J. Baker, H. M. Girvan, S. Matthews, K. J. McLean, M. Golovanova, T. N. Waltham, S. E. J. Rigby, D. R. Nelson, R. T. Blankley, A. W. Munro, ACS Omega 2017, 2, 4705-4724.

[25] A. W. Munro, J. Gordon Lindsay, J. R. Coggins, S. M. Kelly, N. C. Price, Biochimica et Biophysica Acta (BBA) - Protein Structure and Molecular Enzymology 1996, 1296, 127-137.

[26] (a) S. Eiben, H. Bartelmäs, V. B. Urlacher, Appl. Microbiol. Biotechnol. 2007, 75, 1055-1061; (b) Y. Li, D. A. Drummond, A. M. Sawayama, C. D. Snow, J. D. Bloom, F. H. Arnold, Nat. Biotechnol. 2007, 25, 1051-1056.

[27] T. Mandai, S. Fujiwara, S. Imaoka, Biochem. Biophys. Res. Commun. 2009, 384, 61-65

[28] K. L. Harris, R. E. S. Thomson, S. J. Strohmaier, Y. Gumulya, E. M. J. Gillam, Biochimica et Biophysica Acta (BBA) - Proteins and Proteomics 2017.

[29] C. R. Nishida, P. R. Ortiz De Montellano, Biochem. Biophys. Res. Commun. 2005, 338, 437-445.

[30] R.-J. Li, J.-H. Xu, Y. yuecai, N. Wirth, J. Ren, B.-B. Zeng, H. Yu, New J. Chem. 2016, 40, 8928--8934.

[31] (a) L. Liu, R. D. Schmid, V. B. Urlacher, Appl. Microbiol. Biotechnol. 2006, 72, 876-882; (b) D. Minerdi, S. J. Sadeghi, G. Di Nardo, F. Rua, S. Castrignanò, P. Allegra, G. Gilardi, Mol. Microbiol. 2015, 95, 539-554; cA. J. Warman, J. W. Robinson, D. Luciakova, A. D. Lawrence, K. R. Marshall, M. J. Warren, M. R. Cheesman, S. E. J. Rigby, A. W. Munro, K. J. McLean, FEBS J. 2012, 279, 1675-1693; dY.-C. Yin, H.-L. Yu, Z.-J. Luan, R.-J. Li, P.-F. Ouyang, J. Liu, J.-H. Xu, ChemBioChem 2014, 15, 2443-2449.

[32] (a) C. von Bühler, P. Le-Huu, V. B. Urlacher, ChemBioChem 2013, 14, 2189-2198; (b) K. Zhang, S. El Damaty, R. Fasan, JACS 2011, 133, 3242-3245.

[33] (a) J. Brummund, M. Müller, T. Schmitges, I. Kaluzna, D. Mink, L. Hilterhaus, A. Liese, J. Biotechnol. 2016, 233, 143-150; (b) M. T. Lundemo, J. M. Woodley, Appl. Microbiol. Biotechnol. 2015, 99.

[34] (a) I. Kaluzna, T. Schmitges, H. Straatman, D. van Tegelen, M. Müller, M. Schürmann, D. Mink, Org. Process Res. Dev. 2016, 20, 814-819; (b) K. Zhang, B. M. Shafer, M. D. Demars, 2nd, H. A. Stern, R. Fasan, J. Am. Chem. Soc. 2012, 134, 18695-18704; (c) V. Tyagi, H. Alwaseem, K. M. O'Dwyer, J. Ponder, Q. Y. Li, C. T. Jordan, R. Fasan, Biorg. Med. Chem. 2016, 24, 3876 - 3886; (d) P. Bracco, D. B. Janssen, A. Schallmey, Microbial Cell Factories 2013, 12, 95-95.

[35] V. R. Dodhia, A. Fantuzzi, G. Gilardi, J. Biol. Inorg. Chem. 2006, 11, 903-916.

[36](a) M. J. Cryle, R. D. Espinoza, S. J. Smith, N. J. Matovic, J. J. De Voss, Chem Commun (Camb) 2006, 2353-2355; (b) M. A. Noble, C. S. Miles, S. K. Chapman, D. A. Lysek, A. C. MacKay, G. A. Reid, R. P. Hanzlik, A. W. Munro, Biochem. J 1999, 339, 371-379.

[37] R. Fasan, M. M. Chen, N. C. Crook, F. H. Arnold, Angew. Chem. 2007, 119, 8566-8570.

[38] T. Omura, R. Sato, The Journal of Biological Chemistry 1964, 239, 2370-2378. 